\title{
CYSTINURIA: METABOLISM OF THE DISULFIDE OF CYSTEINE AND HOMOCYSTEINE *
}

\author{
BY GEORGE W. FRIMPTER †
}

(From the Department of Medicine, The New York Hospital-Cornell University Medical Center, New York, N. Y.)

(Submitted for publication June 14, 1963; accepted September 6, 1963)

The isolation and identification of the asymmetrical disulfide of L-cysteine and L-homocysteine, hereafter referred to as "mixed disulfide," were previously described (1). At that time the amino acid had been found only in the urine of patients with cystinuria.

This paper attempts to explain the origin and significance of the mixed disulfide. In approaching this work, I first assessed the natural occurrence of mixed disulfide. To increase the compound's sensitivity to detection in a complicated area of the chromatogram, it was rendered radioactive by the administration of $\mathrm{L}$-methionine- $\mathrm{S}^{35}$. The radioactive mixed disulfide was isolated from the urine of a patient with cystinuria after he was fed L-methionine- $S^{35}$, and the specific activities of the two sulfur atoms were compared to each other and to cystine sulfur. The mixed disulfide, synthesized with $\mathrm{S}^{35}$, was administered to a patient with cystinuria, and its fate was studied. Finally, to define the role of the kidney in metabolism of the compound, concentrations in renal venous blood were compared with those in arterial blood.

\section{METHODS}

Free amino acids of urine and plasma were measured by the method of Spackman, Stein, and Moore (2). $\mathrm{S}^{35}$ labeled, mixed disulfide is $100 \pm 3 \%$ recoverable when added to urine or to plasma prior to picric acid precipitation of proteins (3). The compound is, however, unstable under the conditions suggested by Stein and Moore for oxidation of cysteine to cystine for chromatography (4). Accordingly, specimens were analyzed without this step, except when examination for the possible occurrence of homocysteine was desirable. Radioactive mixed disulfide, when added to plasma, dialyzed from cellophane in a manner consistent with its being free and unbound to plasma proteins (5). Fractions of the column effluent were collected by a stream-splitting technique (6).

* This study was supported by grants H-4148 and FR-47 from the National Institutes of Health, U. S. Public Health Service.

$\dagger$ Senior Research Fellow, New York Heart Association.
Radioactivity in fractions of column effluent was determined by liquid scintillation counting. Two-ml fractions were poured directly into counting vials, and the fraction collection tubes were rinsed into the counting vials with $10 \mathrm{ml}$ of a dioxane phosphor system. ${ }^{1}$ This method yielded an over-all counting efficiency of $30 \%$.

For identification of mixed disulfide in urine, fractions were collected by the stream-splitting technique. The pooled fractions containing the material were desalted on Dowex $50 \times 4\left(\mathrm{H}^{+}\right)(7)$ and evaporated to dryness. The specimens were then subjected to oxidation with performic acid (8), and the resultant cysteic and homocysteic acids were determined by 2 -dimensional paper chromatography, with butanol:acetic acid: water (120: $30: 50)$ versus butanol: pyridine: water (1:1:1) (9). The Ninhydrin colored spots were eluted with an ethanolic copper sulfate solution and compared with standards in a spectrophotometer (10).

Fifty $\mu \mathrm{c}$ of L-methionine-S $\mathrm{S}^{35}$ with a SA of $17 \mu \mathrm{c}$ per mg was administered orally to a cystinuria patient who was fasting and had just voided urine. This patient had no evidence of urinary calculi and was known to have normal renal function, including normal inulin clearance. During the 24 hours following administration of the isotope, urine was collected fractionally at 1.25 hours, 5.25 hours, and 6.0 hours; the urine from 6 to 24 hours was collected in one vessel. Samples of each specimen were analyzed for total radioactivity by liquid scintillation counting. Cystine and mixed disulfide were isolated chromatographically on the $150-\mathrm{cm}$ column, as previously described, from portions of the 0 to $1.25-, 5.25$ to 6-, and 6 to 24-hour specimens. These fractions were desalted and lyophilized. Performic acid oxidation split the S-S bond ( 8 , and the specimens were dried on the rotary evaporator. Five-tenths $\mathrm{ml}$ of water was added to the flasks, and several different microliter amounts, in duplicate, were spotted on Whatman 3 filter paper for chromatography of the cysteic and homocysteic acids. Multiple amounts of standard solutions of these compounds were used for comparison. Descending chromatography with butanol:acetic acid: water (120:30:50) was run for 40 hours. This procedure resulted in the cysteic and homocysteic acids' running 185 and $220 \mathrm{~mm}$, respectively, from the origin. Addition of nonoxidized, standard solutions of cystine and mixed disulfide revealed

1 Naphthalene, $50 \mathrm{~g}$; 2,5-diphenyloxazole, $7 \mathrm{~g}$; 1,4-bis2-(4-methyl-5-phenyloxazolyl) benzene, $50 \mathrm{mg}$; and enough dioxane to make $1 \mathrm{~L}$. 
that these were separated from the cysteic and homocysteic acids. No unreacted cystine or mixed disulfide was encountered on the paper chromatograms. After color development, spots were eluted, and micromolar values were determined for cysteic and homocysteic acids by comparison with standards. The duplicate spots were eluted with $80 \%$ ethanol; radioactivity was determined by liquid scintillation counting. Recovery studies showed that the Ninhydrin reaction did not appreciably interfere with counting, and an over-all efficiency of $25 \%$ was obtained.

For the infusion of the mixed disulfide into the tail vein of a rat, $20 \mathrm{mg}$ was dissolved in $35 \mathrm{ml}$ of $0.6 \%$ saline with $\mathrm{pH}$ adjusted to 7.4 with sodium bicarbonate. A similar solution without amino acid was infused, and urine specimens were collected. The solution containing the amino acid was then substituted.

To study metabolism of the compound in a patient with cystinuria, radioactive mixed disulfide was prepared with $\mathrm{S}^{35}$ on the cysteine sulfur. This was done by sodium reduction of L-cystine- $\mathrm{S}^{35} 2$ in liquid $\mathrm{NH}_{3}$ (11) followed by reaction with L-homocysteine prepared from L-homocysteine thiolactone hydrochloride ${ }^{3}$ (12). The reaction mixture was brought to $\mathrm{pH} 7.5$ with $\mathrm{NaHCO}_{3}$ and oxygenated at room temperature for 3 hours. The mixed disulfide, $S^{35}$ labeled, was chromatographically separated on an Amberlite IR-120 column from the reaction's other products, cystine- $\mathrm{S}^{35}$ and homocystine without label (1). To minimize losses, it was elected to separate the material from the citrate buffer with an ion-exchange resin, rather than to attempt crystallization. Accordingly, fractions containing mixed disulfide were passed into a small column of Dowex $2 \mathrm{OH}^{-}$washed with water; the compound was removed with $\mathrm{N}$ acetic acid (13) and lyophilized. Dissolved in water, samples of the material were assayed for radioactivity and amino acid content. Approximately $22.9 \mu \mathrm{c}$ was diluted in $100 \mathrm{ml}$ of saline, autoclaved, and infused intravenously over a 4-hour period. Chromatography of this solution revealed that it also contained cystine, with $40 \%$ of the radioactivity, and homocystine, which was not radioactive. Urine was collected from the beginning of the infusion. Urine sulfate was precipitated with benzidine (14) and counted on planchettes with a gas-flow counter. The over-all recovery and efficiency were $13.7 \%$.

Renal extraction of amino acids was measured by comparing renal venous plasma concentrations to arterial plasma concentrations, simultaneously obtained. Left renal vein catheterization was performed via the femoral vein.4 Peripheral arterial plasma concentration

2 Obtained from Schwarz Bioresearch, Inc., Orangeburg, New York.

${ }^{3}$ Obtained from Nutritional Biochemicals Corp., Cleveland, Ohio.

4 Certain restrictions were placed on the selection of patients for this study. Since the procedure is not without hazard, only patients with two well-functioning kidneys were used. Patients with calculi in the renal pelvis were avoided because they are potential candidates for was taken to be representative of renal arterial plasma concentration. The left renal vein blood was diluted by an unknown amount of left spermatic vein blood. Blood was prepared by the method of Brigham, Stein, and Moore for cysteine (as carboxymethylcysteine) and cystine (15). The carboxymethylcysteine peaks were superimposed upon small methionine sulfoxide peaks. The latter were evaluated separately in plasma processed according to the technique of Stein and Moore, without, however, the oxidation step (4), and deducted from the area of the carboxymethylcysteine peaks.

\section{RESULTS}

The occurrence of mixed disulfide in the normal human. Normal urine does not contain mixed disulfide in amounts detectable by the Spackman, Stein, and Moore technique (2). This is largely because there is insufficient material present; an additional factor might be, however, that this area of the normal chromatogram is somewhat complicated by the number of compounds present in trace amounts (Figure 1).

To evaluate the possibility that the amino acid occurs normally but in trace concentrations, measures were taken to increase the sensitivity for detection. Fifty $\mu \mathrm{c}$ of L-methionine- $\mathrm{S}^{35}$ was administered orally in a single dose to two subjects without liver or kidney disease. Blood, obtained at 6 and 24 hours, was immediately processed for ion-exchange chromatography. Urine was collected for 24 hours and preserved by refrigeration

surgery. Patients had not recently suffered any complication, such as the passage of stones, since the latter might compromise the desirability of giving the patient a methionine load to increase blood concentrations of the mixed disulfide. Patients were preferably large people, so that a large catheter might be introduced to facilitate withdrawal of blood. Finally, the patients were volunteers for the procedure. In a preliminary study, a patient was not given a methionine load, and significant peaks of mixed disulfide were not detected. In another patient, the renal vein blood was obtained at the time of pyelolithotomy. Insignificant a-v differences were obtained; however, it became apparent that the kidney was not functioning, and nephrectomy was later required. The patient from whom data are reported was patient F. C. in Table II. This patient, who filled all the criteria listed above, excreted the highest amount of mixed disulfide and might have the highest blood levels. One limitation of the technique is that leaving the relatively large and stiff catheter in place for an extended period to perform concurrent renal clearance studies seemed unwise. To minimize any effect of water extraction, urinary flow was kept low by restricting fluids, and the urinary bladder was not catheterized for clearance studies. 


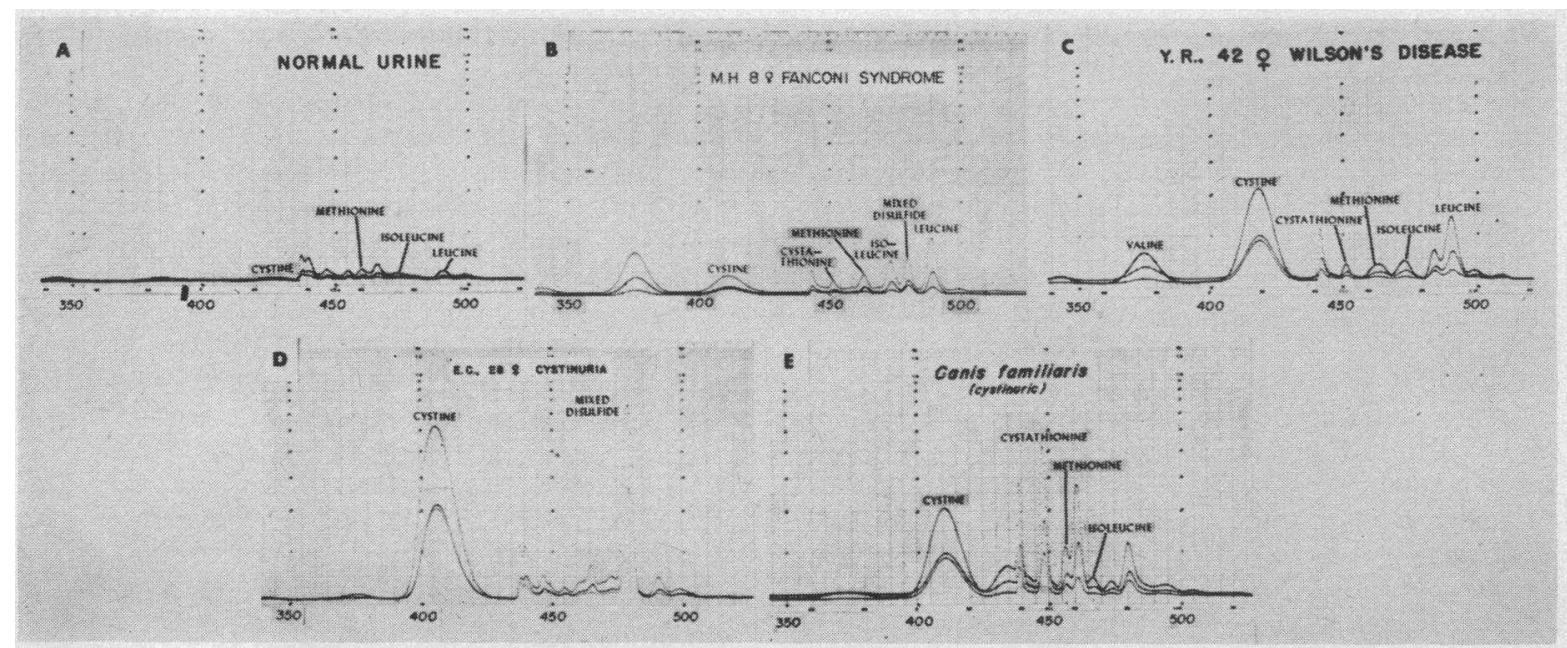

Fig. 1. A) Normal urine. Several Ninhydrin-positive substances are present in trace amounts. B) Spontaneous appearance of mixed disulfide peak in a child with the Fanconi syndrome (Table I, Patient 1). Note that there is a relatively high reading at $440 \mathrm{~m} \mu$ (lower tracing) compared to isoleucine and leucine. C) WILSoN's DISEASE. The unlabeled peak between isoleucine and leucine was shown by isolation and further chemical tests to be the mixed disulfide. D) Typical apPearance of MiXed disulfide and cystine PEAKs in cystinuria. E) Canine CYSTINURIA. The peak at $480 \mathrm{ml}$ with relatively high reading at $440 \mathrm{~m} \mu$ (lower of 3 tracings) is probably the mixed disulfide.

and the addition of thymol crystals. After chromatographic fractionation, $2.0 \mathrm{ml}$-fractions were examined for radioactivity. Peaks of radioactivity were found for sulfate, taurine, cystine, cystathionine, and methionine. ${ }^{5}$ Chromatography of the urine from one of these subjects showed a significant peak corresponding to the mixed disulfide. After corrections for efficiency and decay, $1.3 \times 10^{4}$ counts above background were found in the mixed disulfide area. This, in the 24 hours following administration, indicated that the subject excreted $0.012 \%$ of the administered methionine as the mixed disulfide. Urine from the other subject revealed a few counts above background in the area under question, but these

\footnotetext{
5 That these compounds were radioactive was, of course, expected. The relative amounts of radioactivity contained in the peaks were not quantitatively determined. In finding the relatively high degree of radioactivity contained in the mixed disulfide, as opposed to the low radioactivity anticipated, technical limitations were encountered (for example, when large amounts of urine were chromatographed, amino acids and unknown substances in the counting vial precipitated). In addition, the relative amounts of these compounds excreted would depend on various factors, including the distribution of dietary sulfur, which was not studied. That these compounds were radioactive is important, however, as evidence that the methionine $\mathrm{S}^{35}$ was metabolized.
}

were not statistically significant. None of the plasma specimens contained any radioactivity either in the area of the mixed disulfide or of homocystine, whether or not air-oxidation of the - $\mathrm{SH}$ groups was performed (4).

To increase the concentration of the mixed disulfide for its determination in plasma, $12 \mathrm{~g}$ of L-methionine was given in divided oral doses on 2 successive days to a subject without liver or kidney disease. On the morning of the second day of nonradioactive methionine loading, he was given $50 \mu \mathrm{c}$ of $\mathrm{L}$-methionine- $\mathrm{S}^{35}$. Urine was collected throughout the day. Blood specimens were drawn at 2, 4, 6, and 24 hours to minimize the possibility of missing the peak of mixed disulfide activity in the blood plasma. The picric acid filtrates from each specimen were pooled, and 10 $\mu$ moles of nonradioactive mixed disulfide was added as a carrier. Chromatography of $58.3 \mathrm{ml}$ of the pooled plasma filtrate and counting as described revealed a significant radioactive peak $\left(6.8 \times 10^{3}\right.$ uncorrected counts above background) of the mixed disulfide. $S^{35}$ peaks were also found for sulfate, taurine, cystine, cystathionine, and methionine (see footnote 5).

Occurrence of mixed disulfide in diseases other than cystinuria. To determine the specificity of 
the mixed disulfide for cystinuria, urine from several patients with other amino-acidurias was examined by chromatography. Occasionally, a small peak corresponding to mixed disulfide was seen in urine specimens obtained from patients with the Fanconi syndrome (Figure 1, B) or those with Wilson's disease (Figure 1, C). These patients had a marked generalized amino-aciduria. In a child with the Fanconi syndrome (Patient 1 ) and an adult with Wilson's disease (Patient 2), the amounts of the compound were sufficiently large to calculate excretion and permit collection of fractions containing the mixed disulfide and further identify them (Table I). In two other patients with the Fanconi syndrome, oral methionine loading was followed by disulfide excretion sufficient to permit chromatographic isolation and subsequent confirmation of the identity of the compound. An adult (Patient 3 ) received $15 \mathrm{~g}$ of L-methionine in divided doses daily for 2 days, and urine was collected during the second 24 hours. A child (Patient 4) was given a dose equivalent on a weight basis. The urine of $\mathrm{Pa}$ tient 3 had a small peak in the area corresponding to the mixed disulfide before methionine administration, but that of Patient 4 had none. In both of these patients there was a considerable peak corresponding to the mixed disulfide after methionine loading (Table I). Fractions containing the substance were pooled, desalted, and subjected to performic acid oxidation and paper chromatography. Equimolar amounts of cysteic acid and homocysteic acid were demonstrated in the fractions from urine of all 4 patients.

Ion-exchange chromatography of deproteinized plasma from patients with uremia has been de-

\section{TABLE I}

Asymmetrical disulfide in the urine of patients with diseases other than cystinuria

\begin{tabular}{lcc}
\hline \multicolumn{1}{c}{ Patient } & $\mathrm{SO}_{4}$ & Asymmetrical disulfide \\
\hline & $\mathrm{g} /$ day & \\
1. Child, Fanconi syndrome & & $1.30 \mathrm{mg}$ per $100 \mathrm{ml}$ \\
2. Adult, Wilson's disease & & $1.07 \mathrm{mg}$ per $100 \mathrm{ml}$ \\
3. Adult, Fanconi syndrome & & \\
$\quad \begin{array}{l}\text { Before methionine loading } \\
\text { After methionine loading }\end{array}$ & 10.11 & $25.9 \mathrm{mg}$ per 24 hours \\
$\begin{array}{c}\text { 4. Child, Fanconi syndrome } \\
\text { Before methionine loading } \\
\text { After methionine loading }\end{array}$ & 0.79 & 0 \\
\hline
\end{tabular}

scribed by Woods, Rubin, and Luckey (16), who observed that "several unidentified Ninhydrin reactive substances" were present in the plasma of patients with uremia. In this laboratory, chromatograms of the deproteinized plasma from patients with uremia have consistently shown a peak between isoleucine and leucine. To establish more definitely that this peak was the mixed disulfide, $50 \mu \mathrm{c}$ of $\mathrm{L}$-methionine- $\mathrm{S}^{35}$ was administered orally to a patient without amino-aciduria who had a terminal chronic renal disease (blood urea nitrogen $240 \mathrm{mg}$ per $100 \mathrm{ml}$ ). Blood specimens drawn at 2, 4, 6, and 24 hours were deproteinized, a carrier of nonradioactive mixed disulfide was added, and the pooled specimen was chromatographed. The peak between isoleucine and leucine was significantly radioactive. Amounts insufficient for further chemical analysis were obtained. However, the presence of radioactivity in the characteristic peak is presumptive evidence that this was the mixed disulfide.

Occurrence of mixed disulfide in human and canine cystinuria. The mixed disulfide was invariably found in the urine of 15 patients with cystinuria (Figure 1, D). Fifteen to $224 \mathrm{mg}$ were excreted daily (Table II). There was no consistent relationship to the amount of cystine, ornithine, lysine, or arginine excreted. Deproteinized plasma from these patients with cystinuria did not contain the mixed disulfide in amounts detectable by the Spackman, Stein, and Moore technique. Urine from a Dachshund with cystine calculi contained large amounts of cystine, ornithine, and lysine, but no arginine. There was a peak with the characteristics of mixed disulfide (Figure 1, E).

Origin and metabolic fate of mixed disulfide. To determine the origin of the mixed disulfide, 50 $\mu \mathrm{c}$ of L-methionine- $\mathrm{S}^{35}$ was administered orally to a patient with cystinuria, and urine was collected as the patient voided. The specific activities of the cysteic and homocysteic acids processed from mixed disulfide and from cystine in the urine are shown in Table III. Radioactive mixed disulfide was not detected in deproteinized plasma obtained when considerable radioactive mixed disulfide was found in urine. No radioactivity was found in the homocystine area of either plasma or urine chromatograms. Plasma specimens, however, revealed radioactive sulfate, taurine, cystine, 
TABLE II

Amino acid excretion in 15 patients with cystinuria

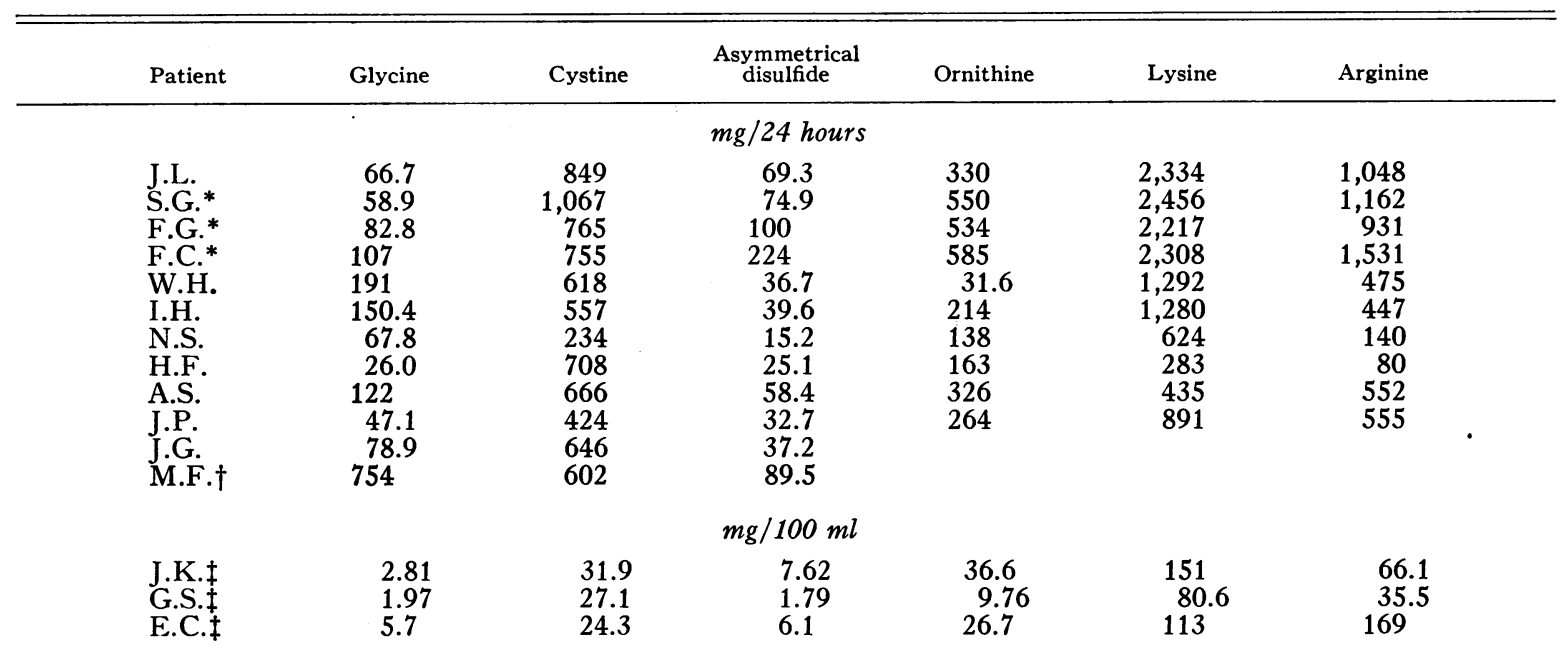

* Unrestricted diet (see text).

† This patient also demonstrated a defect of glycine excretion and possible tubular excretion of cystine (17). All other amino acids were excreted in normal amounts by these patients.

$\ddagger$ Twenty-four-hour urine collections were not obtained on these patients.

cystathionine, and methionine. With corrections for efficiency, decay, and color of the specimens, $15 \%$ of the administered counts was excreted within 24 hours.

For determination of the effects of the mixed disulfide per se, it was infused into the tail vein of a rat. The infusion resulted in an increase in taurine excretion relative to creatinine from 0.94 $\mu$ mole per $\mathrm{mg}$ of creatinine to $2.94 \mu$ moles per $\mathrm{mg}$ of creatinine. Except for the increased taurine excretion, no amino-aciduria was induced by the mixed disulfide.

To explore the possibility that the mixed disulfide is excreted in cystinuria consequent to the absence of some mechanism for its normal disposal, $S^{35}$-labeled, mixed disulfide was adminis-

TABLE III

\begin{tabular}{|c|c|c|c|c|}
\hline \multicolumn{2}{|c|}{ From cystine } & \multicolumn{3}{|c|}{ From asymmetrical disulfide } \\
\hline & & & & Homocysteic acid \\
\hline Specimen & acid & acid & acid & Cysteic acid \\
\hline hours & & $\begin{array}{c}\text { cpm per } \\
\text { umole }\end{array}$ & & \\
\hline $0-1.25$ & 330 & 982 & 8835 & 9.0 \\
\hline $5.25-6$ & 330 & 417 & 2630 & 6.3 \\
\hline $6-24$ & 190 & 274 & 333 & 1.2 \\
\hline
\end{tabular}

tered to a patient. Radioactivity was found largely in urine sulfate precipitated with benzidine. The distribution of radioactivity in the chromatogram from the urine in the first 24 hours after the beginning of collection is shown in Table IV. In the 24 hours following administration, the patient excreted $19.5 \%$ of the radioactivity. Mixed disulfide in the urine contributed only $1.12 \%$ of the total urinary radioactivity, although mixed disulfide constituted $60 \%$ of administered radioactivity.

Renal extraction of amino acids. Because plasma concentrations of the mixed disulfide could not be easily and accurately determined, studying

TABLE IV

Distribution of administered and urinary $S^{35}$

\begin{tabular}{|c|c|c|c|}
\hline \multicolumn{4}{|l|}{ Administered } \\
\hline \multicolumn{2}{|c|}{$\begin{array}{l}\text { Cystine }\left(\mathrm{S}^{35}-\mathrm{S}^{35}\right)-\ldots \ldots \\
\text { Mixed disulfide }\left(\mathrm{S}^{35}-\mathrm{S}\right)-\end{array}$} & \multicolumn{2}{|c|}{$\begin{array}{l}2.025 \times 10^{7} \text { counts } \\
3.053 \times 10^{7} \text { counts }\end{array}$} \\
\hline & & \multicolumn{2}{|c|}{ Excreted radioactivity } \\
\hline 24-hour urine & $\begin{array}{l}\text { Counts } \\
\times 10^{6}\end{array}$ & $\begin{array}{l}\% \text { of } \\
\text { adminis- } \\
\text { tered }\end{array}$ & $\begin{array}{c}\% \text { of } \\
\text { total } \\
\text { excreted }\end{array}$ \\
\hline $\begin{array}{l}\text { Mixed disulfide } \\
\text { Cystine } \\
\text { Sulfate }\end{array}$ & $\begin{array}{l}0.118 \\
2.95 \\
6.75\end{array}$ & $\begin{array}{l}0.233 \\
5.85 \\
13.40\end{array}$ & $\begin{array}{r}1.12 \\
30.10 \\
68.78\end{array}$ \\
\hline
\end{tabular}


TABLE V

Renal extraction of amino acids

\begin{tabular}{ll}
\hline \multicolumn{1}{c}{ Amino acid } & $\frac{\mathrm{A}-\mathrm{V}^{*}}{\mathrm{~A}}$ \\
\hline Proline & .041 \\
Glycine & .092 \\
Isoleucine & .029 \\
Phenylalanine & .016 \\
Methionine & .076 \\
Cystine & .059 \\
Cysteine & .39 \\
Mixed disulfide & .42
\end{tabular}

* Arterial concentration-renal venous concentration

arterial concentration

the renal plasma clearance of the compound was impossible. To estimate the clearance of the mixed disulficle, renal venous plasma concentrations of amino acids were compared to those of a simultaneously obtained arterial specimen. The patient was given orally $5 \mathrm{~g}$ of L-methionine 2 hours before the obtaining of blood specimens to assure the presence of detectable amounts of mixed disulfide. The results of this experiment are shown in Table V. [In calculation of $\mathrm{A}-\mathrm{V} / \mathrm{A}$, the areas under the curves for the various amino-acid peaks were used directly (identical amounts were chromatographed) rather than first calculating concentrations, a procedure which tends to "round off" numbers with a loss of sensitivity.] Cystine appeared to be extracted similarly to other amino acids, whereas cysteine was extracted to a supernormal degree. In addition, the mixed disulfide appeared to be cleared to a high degree. The results do not take into account water extraction by the kidney, which should not, however, invalidate the comparison between the various amino acids.

\section{DISCLSSION}

The experiments reported here permit comment on the significance of the new amino acid, the disulfide of L-cysteine and L-homocysteine. The demonstration of radioactive mixed disulfide in the urine of normal subjects after administering L-methionine- $\mathrm{S}^{35}$ suggests that the compound is normally excreted in trace amounts. When methionine turnover was increased by oral loading, the disulfide was also demonstrated in the plasma of a normal subject.

The spontaneous occurrence of a peak with the characteristics of the mixed disulfide in urines of patients with a generalized amino-aciduria also suggests that this is a "normal" amino acid which escapes into the urine in detectable quantities under special conditions. The identification of this peak by chromatographic demonstration of equimolar amounts of the oxidation products, cysteic acid and homocysteic acid, is evidence that this peak was the mixed disulfide. No other sulfurcontaining amino acid has been reported to occupy the same position as the mixed disulfide in the Spackman, Stein, and Moore system (2). Furthermore, the increase in magnitude of the peak following an oral load of methionine confirms the nature of the peak. The suggestion of presence of the mixed disulfide in the plasma of patients with advanced renal insufficiency further indicates that the amino acid has a wide distribution in trace amounts.

The mixed disulfide was invariably found in the urine of patients with cystinuria. In 15 patients, the amounts excreted bore no correlation on a molar basis to other amino acids excreted. The amount of mixed disulfide excreted appeared to be related to methionine content of the diet. This was not specifically studied; however, those patients who were not treated with a low methionine (400 mg) diet excreted higher amounts of disulfide (Table II). The compound's tendency to be unstable was noted, although this was not specifically studied. After administration of L-methionine- $S^{35}$ to a patient with cystinuria, there were a few counts above background in the homocystine area of one chromatogram of urine. The large amount of cystine present compared to the small amount of mixed disulfide might suggest that the mixed disulfide arises by disulfide interchange between cystine and homocystine, exhausting the latter. However, that homocystine has not been found in this laboratory in freshly collected urines militates against this origin of the mixed disulfide. If the compound is merely another diamino amino acid cleared from the plasma of the cystinuria patient at a rate similar to the glomerular filtration rate, it should have sufficient concentration in the blood plasma, at least in the normal individual, to yield an easily detectable Ninhydrin peak. If, however, the mixed disulfide is cleared from plasma at a rate similar to the renal plasma flow, then difficulty might be anticipated in ap- 
preciating the peak in plasma. ${ }^{6}$ This would imply renal tubular secretion or renal production of the amino acid. Renal tubular secretion of amino acids in cystinuria has been suggested by other studies in this laboratory (17). Renal tubular secretion of amino acids under loading conditions has been shown in dogs by Webber, Brown, and Pitts (18) and demonstrated in human $\beta$-aminoisobutyric acid excretion by Armstrong and coworkers (19).

The origin of mixed disulfide from methionine in cystinuria is confirmed by the study in which L-methionine- $\mathrm{S}^{35}$ was administered to a patient. The urine obtained 1.25 hours after feeding the methionine- $S^{35}$ had the highest specific activity of the mixed disulfide of all the specimens examined. The homocysteine sulfur had initially 9 times the specific activity of the cysteine sulfur, but with time these specific activities tended to become equal. Reasons for this might include, first, the contribution to the cysteine side of mixed disulfide by cysteine from other sources, and second, dilution of the labeled cysteine in a larger body pool than the pool for dilution of labeled homocysteine. Similarly, the specific activity of the cysteic acid from mixed disulfide was always higher than the specific activity of the cysteic acid from cystine. This might also be explained on the basis that cystine labeled with $\mathrm{S}^{35}$ was diluted in a larger body pool than was the mixed disulfide.

Mixed disulfide was metabolized by the rat. The contamination of the $S^{35}$ mixed disulfide with $\mathrm{S}^{35}$ cystine limits the interpretation of the experiment on iv administration to the patient with cystinuria. The rather large amounts of $\mathrm{S}^{35}$ excreted as sulfate, however, and the relatively small amount $(1.12 \%)$ excreted as mixed disulfide are compatible with metabolism of mixed di-

${ }^{6}$ For example, in one patient the daily urinary excretion of mixed disulfide was $225 \mathrm{mg}$ or $886 \mu$ moles, and the inulin clearance was $141 \mathrm{ml}$ per minute. Substituting in the formula, $\mathrm{C}=\mathrm{UV} / \mathrm{P}, \mathrm{C}=203,040 \mathrm{ml}$ per 24 hours; $\mathrm{UV}=886 \mu$ moles per 24 hours ; $\mathrm{P}=886 / 203,040=.0044$ $\mu$ mole per $\mathrm{ml}$ or $0.132 \mu$ mole in a $30-\mathrm{ml}$ plasma specimen prepared with picric acid. This amount is easily detectable, although not accurately measured by the technique employed. The renal plasma flow in this patient was not measured but may have been approximately 5 times the inulin clearance. Then substituting in the formula, $\mathrm{C}=$ $\mathrm{UV} / \mathrm{P}, \mathrm{P}=0.00087 \mu$ mole per $\mathrm{ml}$ or $0.0022 \mu$ mole in a $30-\mathrm{ml}$ plasma specimen. This small amount would not be detected by the method used. sulfide to sulfate. The fraction of $\mathrm{S}^{35}$ excreted in 24 hours by the cystinuria patient who received $\mathrm{S}^{35}$ mixed disulfide and $\mathrm{S}^{35}$ cystine was similar to the fraction of $\mathrm{S}^{35}$ excreted in 24 hours by the patient with cystinuria who received L-methionine $\mathrm{S}^{35}$. The possibility of a difference in the rate of metabolism of mixed disulfide between the normal person and the patient with cystinuria cannot be answered from the available data.

The intermediary metabolism of the sulfurcontaining amino acids, as currently understood, does not provide for production of the mixed disulfide. Free cysteine has been demonstrated in deproteinized blood plasma (15). The present study failed to demonstrate free homocysteine in deproteinized plasma or urine. Neither homocystine nor the mixed disulfide was produced by aeration at $\mathrm{pH} 7$ of deproteinized plasma from either normal subjects or from patients with cystinuria after loading with L-methionine- $\mathrm{S}^{35}$. Homocysteine may, of course, be present in the plasma in amounts that are not detectable by these methods. The studies suggest that mixed disulfide is produced in the tissues and cleared rapidly from the blood by the kidneys in cystinuria. The site or sites of production cannot be determined from present data.

The study of renal extraction of amino acids helps to explain the difficulty in determining plasma concentrations despite large urinary excretion of the mixed disulfide. The compound is apparently extracted from the plasma at a rate greater than any other amino acid.

A by-product of this study was the observation that cystine $(-\mathrm{S}-\mathrm{S}-)$ is handled by the kidneys similarly to other amino acids but cysteine (- $\mathrm{SH}$ ) is extracted to a high degree. Consideration of this finding is interesting in light of the experiments of Brand, Cahill, and Harris, who demonstrated that feeding of cystine does not result in increased cystine excretion in cystinuria but that the fed cystine was found as urinary sulfate (20). Also, Brigham, Stein, and Moore (15) and Frimpter and co-workers (17) have shown that cysteine is virtually absent from urine. These data give further support to the previous suggestion (17) that plasma cysteine is oxidized to cystine before its appearance as urinary cystine. The small extraction of cystine, like that of most amino acids, demonstrates a high degree of reab- 
sorption by the renal tubules and agrees with the observation of Rosenberg, Downing, and Segal that cystine does not compete with lysine, arginine, and ornithine for uptake by rat kidney slices, although the three basic amino acids do compete (21). Crawhill, Scowen, and Watts have reported a remarkable and prompt reduction in urinary cystine in cystinuria by the administration of D-penicillamine $(22,23)$. The cystine was accounted for by the excretion of the disulfide of L-cysteine and D-penicillamine. The present report suggests that the disulfide of cysteine and penicillamine $(22,23)$ arises through reaction of the sulfhydryl of cysteine with the sulfhydryl of penicillamine $\left(\beta, \beta_{1}\right.$-dimethylcysteine $)$ in the kidney or urinary tract. This reaction may, of course, be nonenzymatic and occurs readily in vitro, particularly at $\mathrm{pH}$ over 7 and in the presence of air. Unfortunately in the present study, plasma filtrate adequate for chromatography of the basic amino acids did not remain.

The results of the present study are most compatible with asymmetrical disulfide's being a "normal" metabolite that exists in trace amounts in human blood plasma and urine. It is probably metabolized by the normal subject, largely to sulfate. In patients with cystinuria, large amounts are excreted into the urine. The exact mechanism of excretion has not been defined, but the observations suggest an abnormally high renal extraction of plasma mixed disulfide. This study does not take into account the possibility that different rates of formation of mixed disulfide may exist in the normal subject and in patients with cystinuria. It neither rules out nor confirms formation of cystine and the mixed disulfide in the kidneys or in the urinary tract.

\section{SUM MARY}

1. The asymmetrical disulfide of L-cysteine and L-homocysteine is uniformly excreted in the urine of patients with cystinuria. This amino acid was found in the urine of a dog with cystinuria and cystine stone disease. The asymmetrical disulfide was occasionally seen in the urine of patients with generalized amino-aciduria because of the Fanconi syndrome or Wilson's disease. The amount was increased by feeding L-methionine to two patients with the Fanconi syndrome. The disulfide was presumptively demonstrated in the plasma of pa- tients with advanced renal insufficiency. These experiments demonstrated that the mixed disulfide has a wide distribution in trace amounts.

2. The asymmetrical disulfide, labeled with $\mathrm{S}^{35}$, was excreted by a patient with cystinuria after administration of L-methionine-S ${ }^{35}$. The homocysteine sulfur was initially of higher specific activity than the cysteine sulfur.

3. Intravenously administered mixed disulfide was metabolized by a rat and apparently by a patient with cystinuria.

4. It is proposed that the mixed disulfide arises through a mechanism whereby cysteine combines with homocysteine. The data suggest that the amino acid may be a normal metabolite. In cystinuria and in the generalized amino-acidurias, mixed disulfide seems to be cleared rapidly from the plasma by the kidney and appears in the urine.

5. Determination of renal venous and arterial concentrations of amino acids in cystinuria revealed that cystine is extracted to a degree similar to amino acids not considered to be involved in cystinuria. The plasma cysteine, however, is extracted to a high degree. This study suggests that urinary cystine arises largely from plasma cysteine in cystinuria. The asymmetrical disulfide also appears to be extracted to a high degree, although renal production of the amino acid is not ruled out.

\section{ACKNOWLEDGMENTS}

Several physicians, especially Drs. Victor Marshall, Russell Lavengood, J. Edwin Drew, John W. Draper, John Woodward, Joel Clark, and Alexander Bearn, kindly permitted me to study their patients. Dr. Jay Meltzer suggested the administration of L-methionine to his patient with the Fanconi syndrome and cooperated in the performance of the study, as did Dr. W. W. McCrory with his patient. I am indebted to Dr. Myron Schaeffer and Dr. Felix O. Kolb for the urine of the dog with cystinuria. Dr. M. Halpern kindly performed the renal vein catheterization.

Drs. Vincent du Vigneaud, Melvin Horwith, William H. Stein, Ralph E. Peterson, Abraham Mazur, and David D. Thompson contributed immeasurably by their stimulating interest and advice.

The skillful technical assistance of Miss Audrey Bass, Miss Naomi Schechter, and Mrs. Marie Mongelli is gratefully acknowledged.

\section{REFERENCES}

1. Frimpter, G. W. The disufide of L-cysteine and L-homocysteine in urine of patients with cystinuria. J. biol. Chem. 1961, 236, PC 51. 
2. Spackman, D. W., W. H. Stein, and S. Moore. Automatic recording apparatus for use in the chromatography of amino acids. Analyt. Chem. 1958, 30, 1190.

3. Hamilton, P. B., and D. D. Van Slyke. The gasometric determination of free amino acids in blood filtrates by the Ninhydrin-carbon dioxide method. J. biol. Chem. 1943, 150, 231.

4. Stein, W. H., and S. Moore. The free amino acids of human blood plasma. J. biol. Chem. 1954, 211, 915.

5. McManamy, R. H., C. C. Lund, and J. L. Oncley. Unbound amino acid concentrations in human blood plasmas. J. clin. Invest. 1957, 36, 1672.

6. Woods, K. R., and R. L. Engle, Jr. Automatic analysis of amino acids. Ann. N. Y. Acad. Sci. 1960, 87, 764

7. Thompson, J. F., C. J. Morris, and R. K. Gering. Purification of plant amino acids for paper chromatography. Analyt. Chem. 1958, 31, 1028.

8. Schram, E., S. Moore, and E. J. Bigwood. Chromatographic determination of cystine as cysteic acid. Biochem. J. 1954, 57, 33.

9. Smith, I. Chromatographic Techniques. London, Heinemann, 1958.

10. Giri, K. V., A. N. Radhakrishnan, and C. S. Vaidyanathan. Some factors influencing the quantitative determination of amino acids separated by circular paper chromatography. Analyt. Chem. 1952, 24, 1677.

11. Du Vigneaud, V., L. F. Andrieth, and H. J. Loring. The reduction of cystine in liquid ammonia by metallic sodium. J. Amer. chem. Soc. 1930, 52, 4500.

12. DuVigneaud, V., W. I. Patterson, and M. Hunt. Opening of the ring of the thiolactone of homocysteine. J. biol. Chem. 1938, 126, 217.

13. Dreze, A., S. Moore, and E. J. Bigwood. On the desalting of amino acids by ion exchange. Analyt. chem. Acta. 1954, 11, 554.
14. Power, M. H., and E. G. Wakefield. A volumetric benzidine method for the determination of inorganic and ethereal sulfate in serum. J. biol. Chem. 1938, 123, 665 .

15. Brigham, M. P., W. H. Stein, and S. Moore. The concentrations of cysteine and cystine in human blood plasma. J. clin. Invest. 1960, 39, 1633.

16. Woods, K. R., A. L. Rubin, and E. H. Luckey. Effects of dialysis with the artificial kidney on plasma amino acids in uremic patients. Trans. Amer. Soc. artificial intern. Organs 1961, 7, 83.

17. Frimpter, G. W., M. Horwith, E. Furth, R. E. Fellows, and D. D. Thompson. Inulin and endogenous amino acid renal clearances in cystinuria : evidence for tubular secretion. J. clin. Invest. 1962, 41, 281.

18. Webber, W. A., J. L. Brown, and R. F. Pitts. Interactions of amino acids in renal tubular transport. Amer. J. Physiol. 1961, 200, 380.

19. Armstrong, M. D., K. Yates, Y. Kakimoto, K. Taniguchi, and T. Kappe. Excretion of $\beta$-aminoisobutyric acid by man. J. biol. Chem. 1963, 238, 1447.

20. Brand, E., G. F. Cahill, and M. M. Harris. Cystinuria. II. The metabolism of cystine, cysteine, methionine, and glutathione. J. biol. Chem. 1935, 109, 69.

21. Rosenberg, L. E., S. J. Downing, and S. Segal. Competitive inhibition of dibasic amino acid transport in rat kidney. J. biol. Chem. 1962, 237, 2265.

22. Crawhill, J. C., E. F. Scowen, and R. W. E. Watts. Effect of penicillamine on cystinuria. Brit. med. J. 1963, 1, 588.

23. Watts, R. W. E., J. C. Crawhill, and E. F. Scowen. Diminished cystine excretion in cystinuria associated with administration of $\mathbf{D}(-)$-penicillamine (abstract). Clin. Res. 1963, 11, 230. 